\title{
CONDIÇÕES HIGIÊNICO-SANITÁRIAS DE FATIADORES DE FRIOS DE
} PANIFICADORAS

\author{
Lucas Dutra Zanini da Silva Souza ${ }^{1}$, Ana Luiza Pícoli², Bianca Volpato Gurginski ${ }^{2}$, \\ Ariana Ferrari ${ }^{3}$, Daniele Fernanda Felipe ${ }^{2}$ \\ ${ }^{1}$ Mestrando do Programa de Pós-graduação em Tecnologias Limpas da \\ Universidade Cesumar - UNICESUMAR, Maringá-PR, Brasil \\ ${ }^{2}$ Graduado em Nutrição na Universidade Cesumar - UNICESUMAR, Maringá-PR, \\ Brasil \\ ${ }^{3}$ Docente do Programa de Pós-graduação em Tecnologias Limpas da Universidade \\ Cesumar - UNICESUMAR, Maringá-PR, Brasil \\ E-mail: daniele.felipe@unicesumar.edu.br
}

Recebido em: 15/08/2020 - Aprovado em: 15/09/2020 - Publicado em: 30/09/2020

DOI: 10.18677/EnciBio_2020C13

\begin{abstract}
RESUMO
A contaminação microbiológica de equipamentos utilizados em um estabelecimento de alimentação é muito frequente e causa uma baixa garantia de qualidade dos alimentos. Um desses equipamentos são os fatiadores de frios que podem favorecer a contaminação de frios por microrganismos, principalmente se o processo de higienização for inadequado. O objetivo deste trabalho foi avaliar as condições higiênico-sanitárias de equipamentos fatiadores de frios presentes em panificadoras da cidade de Maringá-PR. Foram analisados os fatiadores de frios de 10 panificadoras, sendo utilizada a técnica de esfregaço de superfície empregando-se swabs para coleta. Foram realizadas a pesquisa de bactérias aeróbias mesófilas, bolores e leveduras e de Staphylococcus aureus. Pode ser verificado que $20 \%$ dos fatiadores de frios das panificadoras não se enquadraram em nenhuma das especificações para bactérias aeróbias mesófilas e $30 \%$ não se enquadram em nenhum dos valores para bolores e leveduras, sendo que o fatiador de frios da panificadora $E$ foi o que apresentou menor qualidade microbiológica. A bactéria $S$. aureus foi encontrada em alguns fatiadores, porém, em quantidades menores, sendo que em apenas um dos fatiadores estava em quantidade considerável. Para os estabelecimentos que se encontraram fora das condições adequadas, foi dada a orientação correta para que a unidade se adequasse quanto à higienização dos fatiadores de frios, para diminuir a contaminação dos mesmos, evitando as doenças transmitidas por alimentos.
\end{abstract}

PALAVRAS-CHAVE: higiene, máquina de corte de frios, microrganismos. 


\title{
HYGIENIC-SANITARY CONDITIONS OF COLD SLICER EQUIPMENT IN BAKERIES
}

\begin{abstract}
The microbiological contamination of equipment used in a food establishment is very common and causes a low quality assurance of food. One of these equipments is the cold slicers that can favor the contamination of cold by microorganisms, especially if the hygiene process is inadequate. The objective of this work was to evaluate the hygienic-sanitary conditions of cold slicing equipment present in bakeries in the city of Maringá-PR. The cold slicers of 10 bakeries were analyzed, using the surface smear technique using swabs for collection. Research on aerobic mesophilic bacteria, molds and yeasts and Staphylococcus aureus were carried out. It can be seen that $20 \%$ of bakery slicers did not meet any of the specifications for aerobic mesophilic bacteria and $30 \%$ do not meet any of the values for molds and yeasts, being the slicer of the bakery $E$ what showed lower microbiological quality. The bacterium $S$. aureus was found in some slicers, however, in smaller quantities, and in only one of the slicers it was in considerable quantity. For establishments that were found to be out of adequate conditions, the correct guidance was given so that the unit would be adequate regarding the cleaning of cold slicers, to reduce their contamination, avoiding foodborne diseases.
\end{abstract}

KEYWORDS: hygiene, cold cutting machine, microorganisms.

\section{INTRODUÇÃO}

É de extrema importância que a alimentação venha assegurar a satisfação das necessidades nutricionais e da saúde da população, para isso é imprescindível que essa seja segura e de qualidade (BEZERRA et al., 2020). As Boas Práticas de Fabricação (BPF) quando aplicadas ao manuseio de alimentos em um serviço de alimentação, asseguram que estes cheguem até o consumidor em condições higiênico-sanitárias adequadas necessárias para o atendimento da legislação em vigor (BORTOLIN et al., 2018).

Nos últimos anos, os serviços de alimentação como as padarias, mudaram sua forma de negócio propiciando aos clientes uma grande variedade de produtos, sendo que a maioria destes sãos produzidos no próprio local (ALMEIDA; COUTINHO, 2019). Assim, há necessidade da padronização de um sistema de boas práticas no processo produtivo e de armazenamento, a fim de que qualidade e segurança dos produtos sejam garantidas (BORTOLIN et al., 2018).

Nem sempre os responsáveis por executar as normas do manual de boas práticas o fazem de forma adequada, tornando assim aquele local inseguro para o consumo alimentar e, consequentemente, aumentando o risco de transmissão de doenças por bactérias ou outros vetores (SILVA et al., 2014). Os manipuladores de alimentos devem ser conscientizados da seriedade da higienização correta, seja esta das mãos, dos utensílios ou equipamentos, propondo-se a garantir um alimento de qualidade e diminuir o risco de contaminação para o consumidor (BEZERRA et al., 2020). A capacitação dos funcionários é importante para que possam executar de forma adequada os procedimentos de limpeza e sanitização, e auxiliar na detecção de não conformidades (OLIVEIRA et al., 2019).

No Brasil, os registros apontam que os surtos de DTA (doenças transmitidas por alimentos) ocorrem principalmente nos serviços de alimentação devido à manipulação inadequada dos alimentos e à higienização deficiente dos equipamentos, alimentos e utensílios (OLIVEIRA et al., 2010; OLIVEIRA et al., 
2019). Staphylococcus aureus, Salmonella spp, Listeria monocytogenes e Escherichia coli estão entre os principais microrganismos causadores de doenças transmitidas por alimentos (OLIVEIRA et al., 2010; MARINHEIRO et al., 2015). A presença de patógenos, como o Staphylococcus aureus, pode levar a quadros de intoxicação alimentar. Amostras que apresentam altas cargas bacterianas constituem um risco a saúde dos consumidores, seja pela ação dos microrganismos ou pela ação das enterotoxinas passíveis de serem produzidas (GASPAROTTO et al., 2019).

O procedimento de fatiamento pode favorecer a contaminação de frios, uma vez que ao fatiar alguma amostra já contaminada, se não for realizada a limpeza adequada do fatiador, as amostras seguintes irão se contaminar, estes procedimentos foram analisados por Sena et al., (2018), em amostras de presunto fatiado e máquinas fatiadoras. De acordo com Souza e Garcia-Gomes (2020), a conservação de produtos fatiados é diretamente influenciada pela manipulação, embalagem e armazenamento, sendo assim o manipulador é uma importante fonte de contaminação microbiana por manuseio inadequado e falta de higiene pessoal, em conjunto com a inadequada higienização dos equipamentos e o armazenamento inadequado do produto fracionado.

Marinheiro et al. (2015) no município de Pelotas, RS, ao analisarem 20 amostras de queijo mussarela fatiado constataram que $20 \%$ estavam em desacordo com a legislação, pois apresentaram contaminação por Staphylococcus coagulase positiva acima de $1 \times 10^{3} \mathrm{UFC} / \mathrm{g}$. Entretanto, ao analisarem 20 amostras em peça inteira observaram que todas estavam de acordo com o estabelecido, sugerindo portanto, que a etapa de fatiamento foi responsável pela contaminação das amostras.

Em estudo realizado por Sena et al., (2018), foi constatado que as máquinas fatiadoras foram as prováveis fontes de contaminação de presunto por enterobactérias. A pesquisa dessas bactérias indica as condições de higiene das máquinas fatiadoras, bem como, da manipulação do produto. A presença desses microrganismos mostra deficiência de higienização do manipulador do alimento, como também no fatiamento, as enterobactérias são facilmente inativadas pelos sanitizantes.

Com o aumento de panificadoras no mercado de produtos alimentícios, deuse também o aumento do consumo de alimentos produzidos e processados nestes estabelecimentos, que podem ou não apresentar boas condições de higiene nos equipamentos utilizados e na manipulação de alimentos. Desta forma, o objetivo desse trabalho foi avaliar as condições higiênico-sanitárias de equipamentos fatiadores de frios presentes em panificadoras na cidade de Maringá- PR.

\section{MATERIAL E MÉTODOS}

Foram analisados os fatiadores de frios de 10 panificadoras de Maringá-PR, selecionadas aleatoriamente. Para amostragem foi utilizada a técnica de esfregaço de superfície empregando-se swabs. Os swabs foram passados em área correspondente à $10 \mathrm{~cm}^{2}$ na superfície de contato do fatiador com o alimento. Após a amostragem, os swabs foram colocados em tubos contendo $10 \mathrm{~mL}$ de água salina estéril, e transportados sob refrigeração para o laboratório de microbiologia, onde foram realizadas as análises microbiológicas. Tais análises foram realizadas em triplicata, sendo feita a pesquisa de bactérias aeróbias mesófilas, de bolores e leveduras e de Staphylococcus aureus, seguindo metodologia descrita por Silva et al. (2017). 
A análise de bactérias aeróbias mesófilas foi realizada pelo método de esgotamento em estrias em placas de Petri contendo o meio de cultura Ágar Padrão para Contagem (PCA) e incubação à $37^{\circ} \mathrm{C}$ por $48 \mathrm{~h}$. Bolores e leveduras foram analisados usando o mesmo método, mas sendo empregado o Ágar Batata Dextrose e incubação à $25^{\circ} \mathrm{C}$ por cinco dias. A contagem de Staphylococcus aureus foi feita por espalhamento de $0,1 \mathrm{~mL}$ da amostra, com auxílio da alça de Drigalski, em superfície de Ágar Baird-Parker com incubação à $37^{\circ} \mathrm{C}$ por $48 \mathrm{~h}$.

Após, os dados foram tabulados e analisados. Os resultados foram repassados para as panificadoras, sendo que para os resultados acima do limite permitido, foi realizado um treinamento na panificadora correspondente, quanto às boas práticas de higiene dos fatiadores de frios.

\section{RESULTADOS E DISCUSSÃO}

Os utensílios e equipamentos empregados em estabelecimentos que comercializam alimentos não podem constituir risco para a saúde, não devendo comprometer a higiene dos alimentos e nem serem fontes de contaminação (KOCHANSKI et al., 2010). A Tabela 1 mostra os resultados obtidos nas análises microbiológicas das diferentes amostras obtidas a partir dos fatiadores de frios presentes em panificadoras.

TABELA 1-Resultados, em UFC/ $\mathrm{cm}^{2}$, das análises microbiológicas dos fatiadores de frios.

\begin{tabular}{llll}
\hline Estabelecimentos & $\begin{array}{l}\text { Bactérias aeróbias } \\
\text { mesófilas }\end{array}$ & $\begin{array}{l}\text { Bolores e } \\
\text { leveduras }\end{array}$ & $\begin{array}{l}\text { Staphylococcus } \\
\text { aureus }\end{array}$ \\
\hline A & negativo & 1 & negativo \\
B & 1 & 1 & negativo \\
C & negativo & negativo & negativo \\
D & 6 & $>250$ & 1 \\
E & $>250$ & $>250$ & 1 \\
F & 1 & 3 & negativo \\
G & 2 & 1 & negativo \\
H & 30 & $>250$ & 5 \\
I & 1 & 1 & negativo \\
J & 86 & 22 & 26 \\
\hline
\end{tabular}

Fonte: Dados da pesquisa

Segundo Oliveira et al., (2008), a OMS (Organização Mundial da Saúde) estabeleceu para superfície de equipamentos que têm contato com alimentos, um índice insatisfatório quando apresenta número de colônias maior que $50 \mathrm{UFC} / \mathrm{cm}^{2}$. Com base nesses valores, as padarias $\mathrm{E}$ e $\mathrm{J}$ apresentaram valores insatisfatórios quanto à bactérias aeróbias mesófilas e $D ; E ; H$ para bolores e leveduras. Os mesmos autores relatam ainda que seguindo a APHA (American Public Health Association), os equipamentos devem apresentar contagem máxima de $2 \mathrm{UFC} / \mathrm{cm}^{2}$ para todos os microrganismos analisados. Desta forma, os estabelecimentos $\mathrm{D} ; \mathrm{E} ; \mathrm{F} ; \mathrm{H} ; \mathrm{J}$ estariam reprovados, ou seja, $50 \%$ destes, sendo os estabelecimentos $\mathrm{D} ; \mathrm{E} ; \mathrm{H} ; \mathrm{J}$ para bactérias aeróbias mesófilas, por bolor e levedura, os estabelecimentos $\mathrm{D} ; \mathrm{E} ; \mathrm{F} ; \mathrm{H} ; \mathrm{J}$, e por Staphylococus aureus, os estabelecimentos $\mathrm{H} ; \mathrm{J}$, como mostrado na Tabela 1.

Considerando a classificação dos equipamentos quanto ao nível de higiene, Oliveira et al., (2008) relatam que valores menores que $10 \mathrm{UFC} / \mathrm{cm}^{2}$ é um nível bom de higiene, entre 10 e $20 \mathrm{UFC} / \mathrm{cm}^{2}$ um nível satisfatório e a partir de $20 \mathrm{UFC} / \mathrm{cm}^{2}$ o 
equipamento já é classificado com um nível insatisfatório. Segundo essa classificação, os estabelecimentos $A ; B ; C ; F ; G ; I$ estariam classificados com níveis bons de higiene para todos os microrganismos analisados. $O$ estabelecimento que apresentou nível insatisfatório para bactérias aeróbias mesófilas seria a panificadora $E ; H ; J$, enquanto que para bolores e leveduras foram as panificadoras $D ; E ; H ; J$, e para Staphylococcus aureus, a panificadora com nível insatisfatório seria J.

Desta forma, considerando as três especificações microbiológicas citadas no presente trabalho, pode ser verificado que os fatiadores de frios das panificadoras $E ; J$, ou seja, $20 \%$ dos equipamentos, não se enquadraram em nenhuma das especificações para bactérias aeróbias mesófilas e os fatiadores das panificadoras $D ; E ; H(30 \%)$ não se enquadraram em nenhum dos valores para bolores e leveduras, sendo que o fatiador de frios da panificadora $E$ foi o que apresentou menor qualidade microbiológica. Quanto à $S$. aureus, o fatiador de frios do estabelecimento $\mathrm{J}$, não atendeu duas especificações microbiológicas.

Em pesquisa realizada por Sena et al. (2018), foi demonstrada a presença de enterobactérias em seis amostras da superfície de máquinas fatiadoras, podendo ser constatado que estas foram as prováveis fontes de contaminação por enterobactérias do presunto analisado.

No presente estudo, os microrganismos encontrados nos equipamentos são nocivos à saúde do indivíduo. Staphylococcus aureus, os quais estão presentes na microbiota dos seres humanos, e são comumente encontrados na região nasal e nas mãos dos indivíduos, podem causar doenças por meio da produção de toxinas, como a síndrome do choque tóxico, gastroenterite, enterocolite e diarreia. Esta bactéria pode estar presente nos alimentos pela contaminação do manipulador, por equipamentos e utensílios higienizados de forma incorreta, ou pelas más condições higiênico-sanitárias (TEIXEIRA; FIGUEIREDO, 2019; REGINATO et al., 2019).

A avaliação de microrganismos como bolores e leveduras é importante para garantir a qualidade dos produtos. Esses microrganismos podem causar alterações indesejadas no sabor e no odor e produzir micotoxinas ou metabólitos secundários que se acumulam no corpo dos consumidores e podem causar problemas de saúde devido aos seus efeitos tóxicos e deletérios (SOUZA et al., 2017).

Pesquisa realizada por Marinheiro et al. (2015), realizou análise microbiológica de amostras de queijos pesquisando Staphylococcus coagulase positiva, coliformes termotolerantes, Salmonella e Listeria monocytogenes. A maioria das amostras fora do padrão correspondia ao produto fatiado, provavelmente por esses produtos passarem por uma etapa a mais (fatiamento) antes de serem embalados, o que faz com que entrem em contato com novas superfícies, equipamentos e manipuladores. Além disso, ao se fracionar qualquer produto sólido, aumenta-se a superfície exposta, o que pode potencializar os riscos de contaminação.

Segundo Freire et al. (2019), produtos frios como presunto pode ser comercializado fatiado, é submetido à intensa manipulação e apresenta alta carga microbiana, o que compromete a qualidade e segurança, sendo que em neste estudo foi encontrada elevada quantidade de microrganismos aeróbios mesófilos e Staphylococcus coagulase positiva. Em pesquisa realizada por Sena et al. (2018), foi identificada a presença de microrganismos aeróbios mesófilos em todas as amostras de presunto fatiado analisadas. Enterobactérias e coliformes totais foram identificados em grande parte das amostras, mostrando carência de boas práticas 
de manipulação e conservação durante as etapas de fracionamento e acondicionamento do presunto (SENA et al., 2018; FREIRE et al., 2019).

Estudo realizado por Oliveira et al. (2019), mostrou que na microbiota do serviço de alimentação, foi observada a ampla disseminação de microrganismos do grupo dos coliformes e Acinetobacter sp., confirmando a inadequação do processo de higienização. Microrganismos patogênicos, como $S$. aureus, foram detectados nas superfícies do serviço de alimentação. Estes achados microbiológicos podem resultar na ocorrência de doenças transmitidas por alimentos.

Após a análise dos resultados, das 10 panificadoras analisadas, cinco foram reprovadas devido à presença de algum tipo de microrganismo. Assim, como $50 \%$ dos estabelecimentos avaliados precisavam de treinamento, quanto à higiene do equipamento de fatiamento de frios, foi apresentado um POP (Procedimento Operacional Padrão) referente à higiene desses equipamentos. Segundo Souza e Garcia-Gomes, (2018), o treinamento e atualização dos funcionários deve ser realizado com frequência, para que as boas práticas de fabricação sejam praticadas, uma vez que funcionários bem treinados irão garantir a qualidade e higiene do produto através da prática de bons hábitos higiênicos durante o fatiamento.

Durante a coleta das amostras, foi verificado que existem diferentes tipos de fatiadores de frios, alguns com superfícies de difícil limpeza. Além disso, há diferenças na localização dos fatiadores nos estabelecimentos, sendo que alguns ficam no balcão onde é feito o atendimento ao cliente e outros ficam dentro da cozinha. Em uma primeira avaliação, foi possível identificar que os fatiadores que ficavam dentro da cozinha aparentavam estar mais sujos, por ter contato com gordura e fumaça provenientes da cocção de outros alimentos e também, por não estar visível aos clientes, o cuidado com a higiene do equipamento poderia ser menor.

Segundo Kochanski et al. (2010), o principal problema de utensílios e equipamentos relaciona-se à superfície que deve ser lisa e de material que dificulte a contaminação dos alimentos. O desgaste destes utensílios e equipamentos aumenta progressivamente com o uso, multiplicando assim a população microbiana. Os utensílios e equipamentos devem ter uma higienização e manutenção adequada e sempre estar em bom estado de conservação.

Diante do exposto, e em concordância com Oliveira et al., (2019), é necessário que os gestores dos serviços de alimentação realizem o controle e a avaliação do processo de higienização dos equipamentos, para assegurar as condições higiênico-sanitárias dos mesmos, de forma que não sejam fonte de contaminação no estabelecimento. Também é necessário realizar a capacitação dos funcionários para que possam executar de forma adequada os procedimentos de limpeza e sanitização, e auxiliar na detecção de não conformidades.

\section{CONCLUSÃO}

As condições higiênico-sanitárias dos fatiadores de frios foram insatisfatórias, uma vez que foi elevado o nível de contaminação por microrganismos, principalmente para bactérias aeróbias mesófilas e para bolores e leveduras. A probabilidade de um alimento que passe pelo equipamento entrar em contato com os microrganismos é elevada. Esse risco proveniente da contaminação cruzada que pode ocorrer, mostra que é necessário adequar o processo de higienização dos equipamentos fatiadores de frios, a fim de minimizar o risco de contaminação e o surto de doenças transmitidas por alimentos. 
Ao realizar o treinamento com os manipuladores dos estabelecimentos reprovados, os mesmos foram informados sobre as consequências que a falta de higienização dos equipamentos pode causar para o consumidor, além da forma correta de realizar tal procedimento, buscando a conscientização dos manipuladores para oferecer um alimento mais seguro.

\section{REFERÊNCIAS}

ALMEIDA, A. A. M.; COUTINHO, D. J. G. Avaliação das condições físicas e higiênicas das áreas de produção em padarias da região metropolitana de RecifePE. Brazilian Journal of Development, v. 5, n. 12, p. 32639-32646, 2019. Disponível em: <https:doi.org/10.34117/bjdv5n12-327>. doi: https:doi.org/10.34117/bjdv5n12-327

BEZERRA, A. R.; DE OLIVEIRA ARCANJO, N. M.; COSTA, B. J. P.; DE FRANÇA MEDEIROS, I. Importância das condições higiênico-sanitárias e boas práticas de fabricação em serviços de alimentação. Revista Brasileira de Gestão Ambiental, v. 14, n. 2, p. 198-204, 2020. Disponível em: <https://editoraverde.org/gvaa.com.br/revista/index.php/RBGA/article/view/7915/758 4>. doi: 10.18378/rbga.v14i2.7915

BORTOLIN, G. C.; MELILLO, R. C. S.; LANÇA, T. Estudo de caso: aplicação de boas práticas de fabricação para indústria de panificação de pequena escala. Revista Engenho, v. 10, n. 1, p. 73-88, 2018. Disponível em: $<$ http://www.portal.anchieta.br/revistas-e-livros/engenho/pdf/revista-engenho-vol145.pdf>.

FREIRE, B. C. F.; DE MELO, E. C. C.; DE ARAÚJO, N. O.; RABELO, J. L. G.; DE PAIVA SOARES, K. M. et al. Microbiological characterization of vacuum-packed and conventionally packed sliced turkey hams marketed in Mossoró, Brazil. Acta Veterinaria Brasilica, v. 13, n. 1, 2019. Disponível em: < https://doi.org/10.21708/avb.2019.13.1.8234>. doi: 10.21708/avb.2019.13.1.8234

GASPAROTTO, P. H. G.; FERREIRA, A. C.; FUVERKI, R. B. N.; DANTAS FILHO, J. V.; DAUDT, C. Avaliação microbiológica para detecção de Staphylococcus aureus em queijos tipo muçarela. Revista Ciência e Saúde Animal, v. 1, n. 1, 2019. Disponível em: < https://doi.org/10.6084/m9.figshare.11312459.v2>. doi: 10.6084/m9.figshare.11312459.v2

KOCHANSKI, S.; PIEROZAN, M. K.; MOSSI, A. J.; TREICHEL, H.; CANSIAN, R. L. et al. Avaliação das condições microbiológicas de uma unidade de alimentação e nutrição. Alimentos e Nutrição Araraquara, v. 20, n. 4, p. 663-668, 2010. Disponível <http://200.145.71.150/seer/index.php/alimentos/article/view/1264/873>.

em:

MARINHEIRO, M. F., GHIZZI, L. G., CERESER, N. D., DE LIMA, H. G., TIMM, C. D. Qualidade microbiológica de queijo mussarela em peça e fatiado. Semina: Ciências Agrárias, v. 36, n. 3, p. 1329-1334, 2015. Disponível em: <https://www.redalyc.org/articulo.oa?id=445744148043>. doi: 10.5433/1679$0359.2015 \mathrm{v} 36 \mathrm{n} 3 \mathrm{p} 1329$ 
OLIVEIRA, M. M. M. D.; BRUGNERA, D. F.; MENDONÇA, A. T.; PICCOLI, R. H. et al. Condições higiênico-sanitárias de máquinas de moer carne, mãos de manipuladores e qualidade microbiológica da carne moída. Ciência e Agrotecnologia, v. 32, n. 6, p. 1893-1898, 2008. Disponível em: < https://doi.org/10.1590/S1413-70542008000600031>. doi: 10.1590/S141370542008000600031

OLIVEIRA, A. B. A. D.; PAULA, C. M. D. D.; CAPALONGA, R.; CARDOSO, M. R. D. I.; TONDO, E. C. Doenças transmitidas por alimentos, principais agentes etiológicos e aspectos gerais: uma revisão. Revista do Hospital de Clínicas e da Faculdade de Medicina Pública, v. 30, n. 3, p. 279-285, 2010. Disponível em: < http://hdl.handle.net/10183/157808>.

OLIVEIRA, A. G. M.; MELO, L.; GOMES, D. B. C.; PEIXOTO, R. S.; LEITE, D. C. A. et al. Hygienic-sanitary conditions and microbial community profile of tables and tableware of a food service located in Rio de Janeiro. Brazilian Journal of Food Technology, v. 22, e2018097, 2019. Disponível em: <https://doi.org/10.1590/19816723.09718>. doi: 10.1590/1981-6723.09718

REGINATO, A. M.; VALIATTI, T. B.; SOBRAL, F. D. O. S.; ROMÃO, N. F. Avaliação microbiológica de queijo tipo mussarela fatiado comercializado em supermercados do município de Ji-Paraná-Rondônia. Revista Brasileira de Higiene e Sanidade Animal, v. 13, n. 1, p. 89-97, 2019. Disponível em: http://dx.doi.org/10.5935/19812965.20190006. doi: $10.5935 / 1981-2965.20190006$

SENA, A. S.; SANTANA, M. V.; NASCIMENTO, G. A.; LIMA, M. A. T.; CARVALHO, L. R. Avaliação microbiológica de presunto fatiado comercializado no município de Pau Brasil-BA. Saúde em Revista, v. 18, n. 50, p. 31-39, 2018. Disponível em: < http://dx.doi.org/10.15600/2238-1244/sr.v18n50p31-39>. doi: 10.15600/22381244/sr.v18n50p31-39

SILVA, N.; JUNQUEIRA, V. C. A.; SILVEIRA, V. V. A.; TANIWAKI, M. H.; GOMES, RAR. et al. Manual de métodos de análise microbiológica de alimentos e água. São Paulo: Blucher, 2017. Disponível em: $<$ https://search.ebscohost.com/login.aspx?direct=true\&db=edsmib\&AN=edsmib.0000 13010\&lang=pt-br\&site=eds-live $>$.

SILVA, M. L. Q.; LOBO, G.; ARRAES, A. A.; AGUIAR, J. J.; VANDESMET, V. C. S. Avaliação higiênico-sanitária dos restaurantes self-services e restaurantes populares da cidade de Juazeiro do Norte (CE) quanto a prevalência de Escherichia coli, Staphylococcus sp. Revista Interfaces: Saúde, Humanas e Tecnologia, v. 2, n. 4, 2014. Disponível em: <http://interfaces.leaosampaio.edu.br/index.php/revistainterfaces/article/view/53/57>.

SOUZA, D. R.; DE SOUSA, G. A.; DE ARAUJO, I. F. B.; PEREIRA, L. M.; DE SÁ BEZERRA, V. et al. Efeitos tóxicos dos fungos nos alimentos. Revinter, v. 10, n. 02, p. 73-84, 2017. Disponível em: < https://doi.org/10.22280/revintervol10ed2.281 >. doi: 10.22280/revintervol10ed2.281 
SOUZA, V. T.; GARCIA-GOMES, A S.; Consumo de presunto cozido fatiado - um alerta para o risco microbiológico. Alimentos: Ciência, Tecnologia e Meio Ambiente, v. 1, n. 6, p. 46-62, 2020. Disponível em: <https://revistascientificas.ifrj.edu.br/revista/index.php/alimentos/article/view/1619/91 $7>$.

TEIXEIRA, C. M. S.; FIGUEIREDO, M. A qualidade microbiológica do leite bovino no brasil associada a Staphylococcus aureus. Revista de Ciência Veterinária e Saúde Pública, v. 6, n. 1, p. 196-216, 2019. Disponível em: <https://doi.org/10.4025/revcivet.v6i1.41172>. doi: 10.4025/revcivet.v6i1.41172 